\title{
A educação ambiental na formação continuada de professores: as práticas compartilhadas de construção
}

\author{
Rossano André Dal-Farra \\ Universidade Luterana do Brasil \\ Mariela Valduga \\ Rede Pública de Ensino de Encantado/RS
}

\section{Resumo}

As múltiplas interfaces entre o global e o local na educação ambiental demandam a construção de práticas de formação de professores nas quais estes participem ativamente do processo, fornecendo subsídios para a realização das atividades. Com essa perspectiva, o presente texto discute os pressupostos subjacentes à realização de ações calcadas nos âmbitos conceituais, atitudinais e procedimentais, indicando a necessidade de incluir a diversidade de experiências dos professores na construção de práticas compartilhadas de formação continuada. Aborda-se, ainda, a importância da inserção de estudos teóricos específicos no âmbito das ciências da natureza em sintonia com o nível de ensino no qual os professores atuam.

Palavras-chave: Educação ambiental. Ensino de ciências. Formação continuada de professores. Ensino fundamental. 


\section{Environmental education in the continued education of teachers: shared construction practices}

The several interfaces between global and local aspects in environmental education require the development of teachers' education practices with the active participation of the teachers, providing subsidies for the implementation of activities. From this perspective, this text discusses the presuppostions underlying the actions based on conceptual, attitudinal and procedural aspects, indicating the need for including the diversity of teachers' experiences in the construction of shared practices of continued teacher education. Additionally, the importance of including specific theoretical studies related to natural sciences, in line with the level of education in which teachers work, is approached.

Keywords: Environmental education. Teacher education. Science education. Continued education of teachers. Elementary school.

\section{La educación ambiental en la educación continuada de profesores: Reflexiones sobre las prácticas compartidas de construcción}

Las múltiples interfaces entre lo global y lo local en la educación ambiental requieren la construcción de prácticas de formación de profesores con la participación activa ofreciendo subsidios para la realización de las actividades. Con esta perspectiva, en el presente trabajo se analiza los supuestos que subyacen las acciones teniendo en cuenta las áreas conceptuales, procedimentales y actitudinales, incluso la diversidad de experiencias de los maestros en la construcción de prácticas compartidas de educación continuada. También se discute la importancia de insertar los estudios teóricos de las ciencias naturales en línea con el nivel de enseñanza en que trabajan los profesores.

Palavras clave: Educación ambiental. Enseñanza de las ciencias. Educación continuada de los profesores. Educación básica. 


\section{Introdução}

A expansão da educação formal no Brasil tem sido um aspecto importante nas últimas décadas, assim como tem demandado a construção de ações educativas que possam contemplar as novas configurações da escola e da sociedade brasileira, na qual os professores se defrontam com alunos com muitas carências no que tange ao conhecimento. Nesse contexto, a ação docente precisa encontrar caminhos efetivos no sentido de contribuir para a inserção dos alunos na sociedade contemporânea, caracterizada pela informação e pela circulação de saberes oriundos de diferentes origens. Diante dos resultados de exames padronizados, assim como de questionamentos em relação ao analfabetismo funcional de uma parcela significativa dos brasileiros, a escola tem sido centro de um debate de grandes proporções, colocando o professor no centro do processo e como alvo de sugestões e prescrições das mais diversas, inclusive em relação à inserção de temáticas/disciplinas no currículo. Por estas razões, há uma premência de realizar a articulação entre os processos de formação e as demandas da sociedade na qual o docente está inserido.

Dados constantes em relatório da Unesco apontam que, em 2008, 95\% das crianças brasileiras de sete a dez anos estavam na escola, embora apenas $80 \%$ chegariam até à quinta série do ensino fundamental, o que dificultava o acesso desses estudantes a conhecimentos e competências relevantes para essa etapa da vida. Acrescente-se, ainda, o fato de as avaliações internacionais apresentarem resultados preocupantes em muitos países do mundo, especialmente nas regiões em desenvolvimento. 0 Pisa, coordenado pela Organização para Cooperação e Desenvolvimento Econômico (OCDE), apontava que os estudantes com menor proficiência em leitura eram oriundos de países com renda média ou baixa, incluindo o Brasil, o que pode ser atribuído a diferentes causas, entre elas os problemas de infraestrutura das escolas e de formação de professores (Unesco, 2008).

Caracterizado por um mosaico de condições geográficas, econômicas, sociais e culturais, o Brasil apresenta uma multiplicidade de sistemas educacionais, com uma grande diversidade de peculiaridades e, consequentemente, necessidades e anseios por parte da comunidade escolar em relação aos aspectos sociais e ambientais. Por essa razão, torna-se relevante para a construção de processos de formação continuada a articulação entre a dimensão local e as diretrizes elaboradas pelos formadores e pelas autoridades educacionais, harmonizando as distintas concepções que nortearão as práticas docentes e proporcionando a ampliação da ressonância entre os diferentes âmbitos do sistema educacional.

No que tange à educação ambiental (EA), as particularidades envolvidas são ainda mais contundentes. As interfaces entre o rural e o urbano, as características 
econômicas da/do região/município, a presença de impactos ambientais oriundos da indústria, do extrativismo ou de atividades de serviço, assim como a inserção da comunidade na produção do impacto antrópico sobre o ambiente, constituem fatores essenciais a serem considerados na construção de uma formação continuada.

Com base em tais premissas, o objetivo deste texto é discutir os princípios subjacentes ao processo compartilhado de formação continuada de professores, com o foco voltado para a EA nas séries iniciais do ensino fundamental. Para essa finalidade, serão cotejadas as informações da produção científica da área com as reflexões a respeito das vivências dos autores com processos de formação de professores.

\section{Os anos iniciais e o ensino de ciências}

Com mais de 17 milhões de matrículas nos anos iniciais do ensino fundamental, - Brasil possui uma grande parcela da sua população entre os sete e onze anos frequentando a escola, assim como mais de 720 mil professores atuando neste nível de ensino. Destes, $61,3 \%$ possui curso superior; $38,2 \%$, o ensino médio; e $0,5 \%$, apenas o ensino fundamental. Entre os possuidores do ensino superior, aproximadamente 97\% cursaram licenciatura (Brasil, 2009a, 2009b). Esse cenário configura uma situação desafiadora - tanto na formação inicial quanto na formação continuada de professores - naquilo que concerne ao atendimento das necessidades da população, especialmente em locais de vulnerabilidade social, caracterizados pela escassez de disponibilidade de acesso à cultura.

Diante das configurações do mundo contemporâneo, no qual as pessoas precisam apropriar-se de saberes oriundos de diferentes áreas, incluindo o ambiente e a saúde, a importância do ensino de ciências nas séries iniciais torna-se cada vez maior, quando se objetiva o desenvolvimento social de todas as regiões que compõem o País.

No pós-guerra, o processo de industrialização, associado ao desenvolvimento científico e tecnológico, passaram a ser inseridos de forma contundente no ensino de ciências. Antes da promulgação da LDB n 4.024/61, as ciências naturais estavam incluídas apenas nas duas últimas séries do antigo ginasial. Apenas a partir da Lei n 5.692 , de 1971, passaram a ser ensinadas em todas as então oito séries do ginásio (Brasil, 1997; Krasilchik, 2006).

Na década de 60 do século XX, o ensino de ciências caracterizava-se por práticas excessivamente expositivas e orientadas para a repetição do conteúdo por parte dos alunos. Posteriormente, principiou a maior valorização dos métodos ativos, incluindo aulas de laboratório, e o incremento da importância do método científico. Os problemas de ordem energética na década de 70 - e uma ainda tímida, embora 
crescente, inserção do discurso ambiental - promoveram mudanças significativas na educação formal, dirigidas pela preocupação com os aspectos sociais e com a busca da construção do conhecimento pelo aluno na perspectiva construtivista (Brasil, 1997; Krasilchik, 2006). Segundo Macedo e Lopes (2002), na própria constituição das ciências como disciplina, a utilidade social da ciência foi o principal mecanismo legitimador, com a biologia ocupando um lugar de destaque, por gerar respostas relevantes para as questões práticas do mundo natural.

Ingressando na década de 90, a preocupação com o impacto ambiental foi crescendo, assim como houve o desenvolvimento de pesquisas específicas no âmbito do ensino de ciências e de matemática. Este incremento proporcionou uma consistente produção acadêmica no Brasil, especialmente nos últimos dez anos, contribuindo para a formação de professores e de estudantes que pudessem integrar os saberes das ciências da natureza e da matemática nas diferentes dimensões de suas práticas sociais.

A Área de Ensino de Ciências e Matemática, denominada Área 46, pela Capes, foi criada em setembro de 2000, sendo que desde 1997 há encontros nacionais bianuais de ensino de ciências, assim como inúmeros eventos na área de matemática, física, química e biologia (Moreira, 2002). A produção científica é crescente, catalogando no ano de 2011 mais de 320 periódicos entre B5 e A1 no Qualis da área, oriundos de diferentes áreas do conhecimento.

Krasilchik e Marandino (2004), abordando a alfabetização científica, apontam a necessidade de as pessoas possuírem o domínio de saberes essenciais ao ensino de ciências, a fim de contribuir para a reflexão a respeito de problemas complexos da atualidade, muitos deles extrapolando as barreiras disciplinares dos currículos.

Entre os temas importantes nesta perspectiva está a EA, cujas características pressupõem a articulação entre as dimensões conceituais, procedimentais e atitudinais, na medida de suas pertinências em cada atividade ou processo educativo desenvolvido, assim como tornam necessária a participação ativa dos professores nas construções curriculares e nas práticas de formação continuada.

Diante da necessidade de ser contínua, de transcender o período escolar e de articular informações de diferentes origens, inclusive midiáticas, a educação científica precisa estar inserida desde cedo na educação formal, aproveitando os diferentes canais de comunicação na contemporaneidade. Não basta apenas que se adquira um vocabulário básico, é necessário que o educando seja capaz de analisar dados concretos de forma crítica, estando ciente de que o conhecimento científico é historicamente construído e está implicado nas relações econômicas e sociais da sociedade na qual é produzido (Krasilchik e Marandino, 2004). 


\section{Educação Ambiental e Ensino de Ciências}

A partir da década de 40 do século XX, a expressão "estudos ambientais" começava a ser utilizada por profissionais de ensino da Grã-Bretanha, mas apenas em março de 1965, durante a Conferência em Educação na Universidade de Keele, Grã-Bretanha, surgia o termo Environmental Education (Dias, 2004). A temática ambiental passou, então, gradativamente a ser incluída com maior ênfase nas agendas políticas internacionais.

Conforme Carvalho (2004), no ano de 1972 a EA passou a ser objeto de discussão de políticas publicas na I Conferência Internacional sobre o Meio Ambiente, realizada em Estocolmo, Suécia, e em 1977 a EA foi tema da I Conferência sobre o assunto em Tbilisi, promovida pela Organização das Nações Unidas (ONU). A mobilização internacional instigou a adoção de políticas e programas nos quais a EA passou a integrar as ações governamentais em diversos países. No Brasil, a EA aparece na legislação desde 1973, com a criação da Secretaria Especial do Meio Ambiente (Sema), constituindo-se no primeiro organismo brasileiro de ação nacional orientado para a gestão integrada do ambiente. Porém, é a partir da década de 80 que a EA se torna mais difundida, sendo incluída no ano de 1988 como direito de todos e dever do Estado, no capítulo relacionado ao meio ambiente na Constituição brasileira (Carvalho, 2004). Posteriormente, ganha ampla repercussão com a realização da RI0-92 e a elaboração da Agenda-21.

Para Carvalho (2004), no momento em que se constituiu como prática educativa, a EA se filiou ao campo da educação formal, como se ocorresse um movimento partindo da sociedade em direção à educação, em consequência da legitimidade conquistada pela temática ambiental na população.

Esta conjunção de eventos, assim como a ampliação da inserção do discurso ambiental na contemporaneidade, proporcionaram, conforme Dias (2004), os instrumentos necessários para a imposição de um ritmo mais intenso da EA no Brasil, o que contribuiu para o desenvolvimento de hábitos, atitudes e valores e refletiu em ações de respeito, cuidado e colaboração com o nosso meio. Conforme os Parâmetros Curriculares Nacionais:

É desejável a comunidade escolar refletir conjuntamente sobre o trabalho com o tema Meio Ambiente, sobre os objetivos que se pretende atingir e sobre as formas de conseguir isso, esclarecendo o papel de cada um nessa tarefa. (Brasil, 1998, 191p).

No Brasil, a Lei no $9795 / 99$ dimensiona a EA a partir dos processos por meio dos quais o indivíduo e a coletividade constroem valores sociais, conhecimentos, habilidades, atitudes e competências voltadas para a preservação do meio ambiente, 
bem de uso do povo, essencial à sadia qualidade de vida e à sua sustentabilidade (Brasil, 1999). A inserção de aspectos ambientais, políticos, econômicos, éticos, sociais e culturais relacionados à ciência e à tecnologia nos planejamentos curriculares está associada à abordagem denominada de Ciência-Tecnologia-Sociedade (CTS). Estas questões são denominadas também de "socioscientific issues (SSI)", ou "questões sociocientíficas". Tais aspectos são inerentes à atividade científica, sendo possível abordar temas como a poluição ambiental, os transgênicos e os recursos energéticos de diferentes formas, seja em grandes temas nos quais os aspectos ambientais, econômicos e sociais estejam imbricados, seja de forma pontual, por meio de fatos e fenômenos do cotidiano relacionados aos conteúdos científicos e às suas aplicações tecnológicas (Santos e Mortimer, 2009).

A capacidade de examinar fenômenos e tomar decisões criteriosas e informadas a respeito de temas científicos tem sido debatida amplamente na literatura relacionada com o ensino de ciências, principalmente pelo fato de esta habilidade contribuir para que as pessoas respondam criticamente às temáticas veiculadas na mídia que sejam relacionadas à dimensão científica. Por definição, as questões sociocientíficas envolvem afirmativas científicas e a argumentação, mas também incluem aspectos políticos e éticos que influem sobre as decisões a serem tomadas, sendo que as pesquisas realizadas em escolas indicam ainda a importância de se abordarem as questões institucionais da ciência (Kolsto, 2005). Diante dos desafios cruciais em relação à inserção do ser humano e aos efeitos da tecnologia de forma crescente no ambiente e em nossas vidas, os debates em relação a estes aspectos demandam sólida formação técnica dos nossos estudantes, contribuindo para que eles tomem decisões cientificamente embasadas, ambientalmente adequadas e socialmente justas.

Nesse processo, é possível enfatizar as questões sociocientíficas buscando a (re) significação da função social do ensino de ciências, objetivando o desenvolvimento de atitudes e valores, e refletindo criticamente a respeito dos desafios da atualidade, sendo o papel do professor de grande importância para este processo, tanto na formação inicial quanto na continuada (Kolsto, 2005; Santos e Mortimer, 2009). Mais do que conhecer os temas sociocientíficos contemporâneos, o estudante precisa compreender as complexas inter-relações entre os diferentes elementos do sistema em estudo, mormente quando envolvem aspectos tão relevantes quanto o saneamento urbano e os reflexos da urbanização sobre o ambiente natural.

Analisando estudos realizados com alunos da escola secundária, Jímenez Aleixandre e Frederico Agraso (2006) abordam aspectos importantes relacionados à tomada de decisões informadas no âmbito dos temas sociocientíficos atinentes ao ambiente. No texto, os autores relatam duas experiências escolares, uma relacionada à gestão ambiental de um rio em região pantanosa, e outra referente a um acidente 
ambiental ocorrido com um petroleiro na costa galega no norte da Espanha, no ano de 2002. Os pesquisadores acrescentam ainda a necessidade de se trabalhar com temas socialmente relevantes, assim como apontam para a importância de os alunos desenvolverem a argumentação frente às grandes questões da atualidade.

Com este olhar, a EA precisa ser abordada num contexto de interdisciplinaridade, atuando não apenas no âmbito das ciências da natureza, mas também no campo econômico e social. Com esse propósito, é necessário o desenvolvimento de práticas educativas nas quais se possam discutir, analisar e avaliar as relações entre o ser humano e a natureza, partindo do próprio contexto no qual a escola está inserida. Em relação à abordagem utilizada, Zakzevski e Sato (2007) afirmam:

Defendemos a idéia de que o meio ambiente é efetivamente um tema transversal, não apenas porque pode ser abordado por todas as disciplinas escolares, mas porque procura relacionar diversos tipos de reflexões: a ecológica, a metodológica e a pedagógica. É também um tema transversal porque coloca sobre uma única mesa pontos de vista e interesses diferentes. (Zakzevski e Sato, 2007, p. 127).

A EA vem sendo um desafio constante em nossas salas de aula, pois nossos alunos estão submetidos diariamente a informações veiculadas midiaticamente, abordando, preponderantemente, aspectos genéricos, como a destruição do planeta, por exemplo. Dessa maneira, é possível fomentar a criação e a formação de valores e atitudes, a construção de conhecimentos e a incorporação de práticas visando à melhoria e à qualidade de vida na comunidade.

\section{A formação de professores e a educação ambiental}

A nova cultura de aprendizagem que se avizinha caracteriza-se pela sociedade da informação, do conhecimento múltiplo e da aprendizagem contínua. (Pozo e Crespo, 2000, p. 27).

Já no final do século passado, os autores espanhóis Pozo e Crespo identificavam as configurações complexas da educação contemporânea, indicando que "a escola não é a fonte primeira e por vezes sequer a principal [fonte] do conhecimento por parte dos alunos em muitos domínios" (idem, p. 27). Os autores indicavam também um processo de descentralização do conhecimento, agora obtido em fontes diversas, demandando o desenvolvimento da autonomia e da aprendizagem contínua por parte dos estudantes.

Realizando um trabalho que articulava EA e educação em saúde por meio do controle da dengue, Einsfeld et al (2009) verificaram que as contínuas inserções midiáticas em 
relação ao tema contribuíam para o desenvolvimento de práticas de prevenção, embora a transposição de alguns aspectos para diferentes situações necessitava de maior detalhamento no âmbito conceitual, algo que apenas os professores poderiam realizar em suas práticas educativas na escola, proporcionando a fundamentação necessária para repensar as ações segundo as peculiaridades de determinadas situações. Nesse processo, não podemos prescindir da formação inicial de professores fortemente calcada na fundamentação conceitual e na educação pela pesquisa dotada da criticidade que caracteriza esta atividade. Cientes de que os saberes circulam entremeados a discursos distintos e, inclusive, contraditórios em alguns aspectos em relação à EA, as releituras que professores podem fazer dos mais variados fenômenos relacionados ao contexto ambiental permitem uma ação mais particularizada na comunidade em que vivem.

Segundo Penteado (2003), a formação da consciência ambiental nos estudantes está vinculada à passagem da escola informativa para a escola formativa, na qual é possível contribuir-se na formação dos indivíduos, capacitando-os a criar e participar das decisões destinadas à resolução dos problemas ambientais. Conforme os Parâmetros Curriculares Nacionais, sendo o ambiente um tema transversal, tornase mister abordar a relação entre os problemas ambientais e os fatores históricos, sociais, econômicos e políticos envolvendo as responsabilidades humanas sobre o ambiente (Brasil, 1997). A partir da integração de saberes, incide a necessidade de fundamentação conceitual e a sua inserção no contexto da comunidade na qual a escola está inserida, revestindo-se de crucial importância para a construção de um processo de formação docente compartilhada o conhecimento das nuances técnicas do impacto ambiental presente nas proximidades da escola. Articulando-se os processos físicos, químicos, biológicos e sociais, é possível proporcionar um domínio maior do contexto ambiental, fazendo com que o professor se sinta convidado a mobilizar os diferentes saberes que possui, assim como seja estimulado a mobilizar os saberes dos seus alunos. 0 estudante jamais olhará para um fenômeno da mesma forma, após conhecê-lo mais profundamente por meio do estudo detalhado dos condicionantes que nele operam e, principalmente, da possibilidade de alterá-lo com ações.

Entretanto, “[...] a proposta de uma formação docente como mudança didática exige, não apenas mostrar as insuficiências da formação ambiental recebida, mas oferecer, ao mesmo tempo, alternativas realmente viáveis" (Carvalho e Gil-Pérez, 2009, p. 40).

\section{Formação Docente Continuada: a construção coletiva e compartilhada}

Para Krasilchik (2006), embora não haja discordâncias evidentes sobre o papel das disciplinas científicas na educação escolar, os resultados obtidos estão longe 
das aspirações compartilhadas por todos que influenciam as decisões curriculares. Discutindo o "pensar lógica e criticamente" nas elaborações curriculares, a autora indica as explicações possíveis para que este processo não ocorra de forma efetiva na aplicação dentro das salas de aula: 1) os professores interpretam de forma diferente o significado deste processo; 2l os professores concordam apenas aparentemente; 3) os objetivos são aceitos, mas os professores não estão preparados para trabalhar o currículo com esta proposta.

Abordando a pesquisa sobre educação em ciências e a formação de professores, Maldaner et al. (2007) apontam o principal desafio dos pesquisadores, que consiste na aproximação entre a produção científica com aquilo que acontece nas salas de aula, indicando a necessidade de ambos construírem maior sintonia na realização de atividades dessa natureza. Para os autores, as experiências vivenciadas indicam que as maiores possibilidades de mudança ocorrem quando os processos são desencadeados no interior das escolas, com a parceria da universidade e demais setores que podem contribuir com a educação.

Discorrendo a respeito dos processos de elaboração de currículos, Krasilchik (2006) afirma a importância da realização de pesquisas prospectivas que possam servir de base para trabalhos com grupos diversificados, apontando que a participação voluntária e a apresentação de trabalhos por parte dos próprios professores em cursos de formação são fundamentais para o sucesso destas ações. Diante de tal desafio, a postura mais condizente dos formadores ao elaborar e executar processos de formação continuada pressupõe o respeito ao "olhar do outro", a participação ativa do sujeito que aprende e o rigor dos princípios teóricos subjacentes ao tema em estudo.

Ampliando o foco de análise, é possível verificar que a consideração histórica da ciência como o único espaço de produção de conhecimento superior atrelado ao discurso predominante da sociedade tecnológica foi sendo questionada a partir das últimas décadas do século XX. Este questionamento não lança dúvidas sobre a capacidade da ciência de gerar saberes válidos, mas questiona a sua exclusividade como espaço de produção de conhecimento (El-Hani e Sepúlveda, 2007).

Os autores supracitados atribuem esta mudança a três grandes fatores: 1) a afirmação do construtivismo como tendência na educação científica, considerando a construção da aprendizagem a partir daquilo que o aluno sabe, ou seja, dos conhecimentos prévios que possui; 2) o foco dos estudos sobre currículo estar voltado para a compreensão dos processos históricos de sua construção; 3) a adoção de uma postura mais cética de determinados grupos sociais em relação à ciência ocidental moderna, tanto pela emergência dos problemas ambientais quanto pelas repercussões sociais resultantes dos processos tecnológicos do período. 
0 debate poderia, de forma simplificada, ser caracterizado por dois extremos. De um lado estão os universalistas epistemológicos defendendo ser a ciência dotada de um caráter universal, e do outro estão aqueles que consideram ser a posição universalista como excludente daquilo que se chama TEK (traditional ecological knowledge, ou conhecimento ecológico tradicional), defendendo a ampliação do conceito de ciência. Posteriormente, surgiu uma posição intermediária denominada de "pluralismo epistemológico", evitando a postura relativista que considera todas as formas de conhecimento como modalidades de ciência e não advogando em favor de uma suposta superioridade da ciência em sua feição ocidental moderna, mas entendendo a importância da demarcação de formas diferentes de conhecimento construídas em condições socioculturais distintas (El-Hani e Sepúlveda, 2007).

Desde as agressivas manifestações dos ecologistas na década de 1970, passando pelos aprofundados estudos do impacto ambiental, chegando ao tênue ponto de união entre as necessidades da geração atual em confronto com o legado às gerações futuras, as manifestações históricas caracterizam um contínuo processo de conflito e conciliação de posições anteriormente antagônicas, gerando posicionamentos muitas vezes intermediários entre polos outrora distintos.

Os saberes oriundos de diferentes perspectivas articulam-se na construção de práticas sociais que possam atender às demandas sociais em suas diferentes dimensões, e a posição dos pesquisadores frente a contextos sociais complexos torna necessária a adoção de um olhar mais sensível às particularidades envolvidas na vida dos professores e da comunidade. Diante desta perspectiva, o compartilhamento pressupõe ouvir o outro e compreendê-lo para, a partir desta escuta, verificar quais seriam as necessidades básicas do contexto em que ele atua. Este processo está associado ao conhecimento das concepções e percepções dos professores, já que “a valorização das culturas locais e o respeito à multiplicidade de experiências, valores e ideias na construção de ações para a sustentabilidade podem ser a chave para uma mobilização comunitária" (Jacobi et al., 2009, p. 75).

Os princípios supracitados se constituem como base para a construção de processos compartilhados de formação continuada, considerando que cada indivíduo possui um conjunto de saberes construídos ao longo da sua vida, por meio de influências do ambiente em que habita e das experiências vivenciadas dentro e fora da escola. Torna-se necessário que os professores reflitam em relação às suas concepções e percepções a respeito do ambiente, assim como do papel de cada indivíduo e da comunidade articulados com os pressupostos teóricos subjacentes aos diferentes domínios das ciências da natureza, da matemática e das ciências humanas, com o fito de construir práticas compartilhadas de ação. 0 objetivo central não consiste na substituição pura e simples de conhecimentos, mas sim na busca de um constante 
repensar de práticas que sejam ao mesmo tempo inovadoras e coadunadas aos processos históricos que caracterizam a comunidade.

Longe de se constituir em uma postura distante e pretensamente superior à comunidade, o processo compartilhado de construção oportuniza aos formadores a identificação dos pontos mais importantes a serem enfatizados na formação continuada. Como afirmam Carvalho e Gil-Pérez (2009), ao proporcionarmos um trabalho coletivo de reflexão e orientarmos as ações de formação como se fossem uma pesquisa dirigida, é possível transformar as concepções iniciais dos professores. As experiências dos autores com a formação inicial e continuada indicam que a efetividade de um processo de formação continuada depende da "adesão", já que a “imposição" e a "pressão" funcionam apenas nos momentos em que são utilizadas, pois quase sempre são seguidas de “abandono" e, pior ainda, de "rejeição”. Analisando processos de formação continuada de professores de ciências realizados em diferentes escolas, Carvalho (2007) indica que a participação voluntária dos professores é necessária, ressaltando também que as dificuldades deles com o conteúdo específico podem constituir-se em obstáculos decisivos para o sucesso das atividades.

Os processos de formação docente continuada devem ser calcados na construção coletiva decorrente do levantamento dos aspectos principais que serão incluídos na abordagem, tanto em relação aos anseios da comunidade de docentes, quanto em relação às demandas de ordem técnica vinculadas à instrumentalização dos professores no âmbito dos fundamentos teóricos subjacentes às ciências da natureza, à matemática e às ciências humanas.

Afirmam Carvalho e Gil-Pérez (2009), citando outros estudos, que a principal dificuldade para o envolvimento de professores em atividades inovadoras está relacionada ao conhecimento específico da ciência. Em tal perspectiva, a obtenção de informações por meio de instrumentos de coleta de dados do tipo questionário, bem como de reuniões de caráter participativo nas escolas, proporciona a todos a possibilidade de opinarem em relação à formação continuada.

Discorrendo a respeito dos processos de elaboração de currículos, Krasilchik (2006) afirma a importância da realização de pesquisas prospectivas que possam servir de base para trabalhos com grupos diversificados, apontando ainda a participação voluntária e a apresentação de trabalhos por parte dos próprios professores em cursos de formação como aspectos fundamentais para o sucesso destas ações. Incorporando as vozes dos professores e construindo de forma compartilhada a formação continuada com base nos conhecimentos prévios dos docentes e por aspectos essenciais que emergem da comunidade em questão, tornase possível levar à comunidade um processo educacional cuja origem é, poder-se-ia dizer, o próprio destino (Valduga e Dal-Farra, 2011). 
A formação continuada de professores pressupõe, tal como se advoga para a aprendizagem dos alunos, a participação efetiva do sujeito para o qual ela se destina, assim como deve estar construída a partir dos conhecimentos prévios dos professores e dos seus questionamentos em relação aos problemas que enfrentam no cotidiano. Por esta razão, as questões culturais subjacentes, bem como os processos políticos e históricos da comunidade na qual os docentes estão inseridos, constituem-se no ponto de partida para a implantação da formação continuada, de acordo com aquilo que o formador detecta como sendo os principais desafios a serem superados. Ressaltese, entretanto, que conhecer o ambiente educativo e compreender as condições de possibilidade nas quais os professores trabalham não significa estar preso a este contexto, mas sim estar ciente das mudanças desejáveis a serem inseridas no processo educativo em questão. Sumarizando uma extensa rede de princípios importantes para a realização da formação continuada, Imbernón (2010) aponta os seguintes aspectos: partir dos interesses e das práticas dos professores envolvidos; construir um clima de escuta e comunicação compartilhada para a construção da aprendizagem participativa; elaborar projetos de trabalho em conjunto, superando as resistências ao trabalho colaborativo; conhecer as diferenças culturais presentes na instituição e respeitá-las.

No item seguinte serão descritas algumas experiências dos autores com a construção de processo de formação no qual os princípios de compartilhamento e de colaboração foram empregados objetivando harmonizar a tríade: "experiências dos professores", "possibilidades e necessidades do contexto educacional em questão" e "aprofundamento teórico".

\section{Vivências e reflexões}

0 que entendemos por colaborar? A resposta, em princípio, é muito simples: colaborar é laborar ou trabalhar com alguém [...], realizar em conjunto uma atividade significativa, o que, por definição, implica o propósito de atingir uma meta ou objetivo relevante e compartilhado. (Monereo e Pozo, 2007, p. 28).

Em atividade de assessoramento, as práticas colaborativas se constituem em pressuposto fundamental das ações, representando uma forma essencial do desenvolvimento de ações que possam efetivamente contribuir para o processo de ensino e aprendizagem, como as experiências com docentes em formação inicial e continuada podem atestar.

A experiência de um dos autores com a formação inicial de professores, na disciplina ciências naturais na educação infantil e nas séries iniciais, apontou alguns aspectos muito importantes a serem considerados. 
0 processo educativo realizado com diferentes turmas do curso de pedagogia sempre foi pautado na articulação entre os pressupostos teóricos oriundos da produção acadêmica do ensino de ciências e as vivências dos estudantes, sendo operacionalizado pela exposição dialogada e pela realização de trabalhos práticos desenvolvidos pelos acadêmicos. As temáticas eram dispostas em grandes eixos, considerando seus desdobramentos, tais como: as cadeias alimentares, como ponto de discussão das interrelações entre os seres vivos e entre eles e os fatores abióticos; e o corpo humano, como gerador de uma ampla gama de atividades relacionadas à saúde.

Com base em tais vivências, é possível afirmar que:

1) Mesmo na formação inicial, a diversidade de experiências e saberes é o que caracteriza a prática educativa compartilhada, algo de contundente relevância para a aprendizagem dos graduandos;

2) 0 encadeamento progressivo dos estudos teóricos, apresentados em ordem crescente de complexidade, com as possibilidades de se construírem práticas educativas concretas e em sintonia com o nível de ensino em questão, enriquece sobremaneira as ações dos alunos, mesmo entre aqueles que já possuem larga experiência na atuação como professores;

3) O desenvolvimento de práticas educativas fundamentadas academicamente está associado à motivação dos estudantes para a realização de estudos aprofundados, ou seja, há uma retroalimentação constante que sustenta os dois processos; e

4) Fundamentalmente, uma postura docente que respeita a perspectiva do outro, inserida nas particularidades intrínsecas à relação professor-aluno quanto aos papéis ocupados por cada um, proporciona a sinergia necessária à emergência dos saberes de todos, assim como o compartilhamento por meio do processo colaborativo.

Os aspectos delineados se coadunam com os princípios importantes apresentados por Imbernón (2010) em relação aos seguintes tópicos: a necessidade de partir dos interesses e das práticas dos professores, a construção de um clima de escuta e comunicação compartilhada para a construção da aprendizagem participativa e a elaboração de projetos de trabalho em conjunto.

Outro aspecto relevante consiste na veiculação das questões teóricas subjacentes ao ensino de ciências que possam fundamentar as práticas educativas dos professores em formação, já que, segundo Carvalho e Gil-Pérez (2009), as questões de conhecimento específico da área se constituem na principal dificuldade para o envolvimento de professores em atividades inovadoras. De fato, a articulação entre as necessidades do contexto e das questões teóricas relevantes para a situação proporciona aos formadores a construção de um processo de formação no qual 
possam ser aprofundadas as temáticas necessárias a serem discutidas e estudadas pelos professores.

Com essa perspectiva, a realização de pesquisas, junto aos professores, que busquem conhecer as necessidades e os anseios que estes possuem em relação à formação continuada se constitui na base da construção dos trabalhos com grupos diversificados. Assim é possível contribuir para que o processo parta dos interesses e das práticas dos docentes, possibilitando ainda a detecção de experiências relevantes a serem incluídas no processo e a elaboração de projetos de trabalho conjuntos e compartilhados (Krasilchik, 2006; Imbernón, 2010).

Imbuídos dessas pressuposições, os autores do presente texto realizaram, junto a professores da rede pública de um município do Rio Grande do Sul, um diagnóstico situacional que serviria de subsídio para a construção de um processo de formação continuada dos docentes com base em suas vivências, percepções e concepções relacionadas com a EA (Valduga, 2011; Valduga e Dal-Farra, 2011). Nesse processo, 79 professores responderam a um instrumento de coleta de dados com questões abertas e fechadas. Do total de professores, 45 atuam no ensino fundamental. As informações coletadas destes últimos serão discutidas neste texto.

As respostas foram estudadas com base na análise de conteúdo, formando categorias que representavam os principais aspectos relacionados com a temática ambiental, objetivando que os professores tivessem a oportunidade de expor as suas próprias necessidades e anseios em relação à formação continuada (Bauer e Gaskell, 2008). Uma parcela dos dados recebeu um tratamento quantitativo, com o fito de realizar uma ponderação que possibilitasse atribuir maior ênfase a determinados aspectos da formação continuada.

Inicialmente, o objetivo foi analisar as concepções de educação ambiental dos professores, visando compreender as questões mais relevantes a serem abordadas em um processo de formação continuada. Foram apresentadas cinco definições de EA, para que os professores as classificassem em ordem decrescente de importância. Os resultados foram os seguintes:

1) Definição $E$ - ênfase na adoção de práticas que proporcionem a sustentabilidade e a diminuição do impacto ambiental no ecossistema.

2) Definição A - ênfase nos conhecimentos e valores que possam tornar os indivíduos mais aptos para a resolução de problemas ambientais.

3) Definição D - ênfase no conhecimento da natureza e das interferências produzidas pelo ser humano sobre ela.

4) Definição $C$ - ênfase na formação de valores e de vivências na construção dos fundamentos utilizados para pensar a EA.

5) Definição B - ênfase nas questões políticas, de justiça social e cidadania. 
As concepções de EA dos professores foram preponderantemente vinculadas às práticas de sustentabilidade e aos problemas decorrentes do impacto ambiental e, em segundo lugar, à conjunção de conhecimentos e valores necessários para a resolução de problemas ambientais. Depreende-se dos resultados que os docentes compreendiam a importância dos domínios conceituais associados à questão dos valores e das práticas sociais que respeitassem o ambiente.

Foram apresentadas, ainda, doze palavras compondo quatro grupos: Al educação formal, B) ambiente natural, C) atitudes e valores e D) problemas ambientais. Os professores atribuíram valores de 1 a 5 em relação à importância de cada item no âmbito da EA. Os resultados apontaram, em ordem decrescente de importância, os seguintes termos: 1) atitudes, 2) escola, 3) aprendizagem, 4) sensibilização e 5) conscientização.

Os itens denominados de poluição, desastres ambientais e indústrias, vinculados ao grupo D, não foram evidenciados pelos professores, assim como os aspectos ligados ao ambiente natural, tais como fauna, flora e ambiente.

Diante de resultados como estes, é possível realizar abordagens ressaltando os tópicos importantes que possam estar esquecidos pelos professores, assim como sugerir atividades passíveis de serem incluídas nas programações curriculares do contexto educacional no qual os mesmos estão vinculados.

Caso se opte pela abordagem de questões específicas de impacto ambiental no âmbito das questões sociocientíficas, ao se obter um cenário aproximado das concepções dos professores, torna-se possível desenvolver atividades conforme indicam Santos e Mortimer (2009), nas quais os aspectos ambientais, econômicos e sociais estão imbricados, incluindo ainda fenômenos do cotidiano relacionados a conteúdos científicos específicos de cada assunto.

No presente estudo, o cotejamento dos resultados obtidos proporcionou a constatação da complexidade envolvida no processo. Ao se ponderar a respeito das definições, verificou-se que houve maior ênfase a aspectos pouco destacados no momento de se realizarem associações entre os doze termos e a EA, indicando a necessidade de problematização, no processo de formação continuada, dos amplos domínios das temáticas ambientais. Mais do que proporcionar um diagnóstico situacional da inserção da temática nas preocupações dos docentes, o processo de construção compartilhada sinaliza os pontos mais importantes a serem atingidos na formação continuada, contemplando não apenas os desejos dos professores mas também as necessidades ambientais da comunidade e do município. Ao mesmo tempo em que atende aos anseios dos professores, a formação continuada pode preencher as possíveis lacunas existentes no âmbito conceitual de forma dialógica com o olhar dos formadores, almejando a harmonização de discursos cuja ressonância 
reside no atendimento às necessidades da comunidade em relação ao ambiente e às peculiaridades locais.

Ao responderem a respeito das disciplinas que deveriam tratar do assunto, os professores indicaram, preponderantemente, ciências, geografia e português. Por outro lado, apenas um reduzido número de docentes assinalou inglês e matemática. Entretanto, dois terços dos professores apontaram que todas as disciplinas deveriam tratar do tema, indicando uma tendência entre eles de abordagem transversal, constatação relevante na construção de uma formação continuada relacionada à EA.

Para Zakzevski e Sato (2007), a transversalidade da temática ambiental decorre não apenas da possibilidade de se realizarem abordagens em todas as disciplinas escolares, mas também da possibilidade de ser trazerem à tona pontos de vista e interesses diferentes e até mesmo contraditórios. A quase totalidade dos professores pesquisados respondeu já haver participado em atividades relacionadas à EA. Os temas mais frequentes relatados foram a questão dos resíduos (lixo), o plantio de árvores, as hortas e o trabalho com a questão dos valores intrínsecos à EA, havendo ainda uma grande diversidade de assuntos inseridos nas atividades como um todo, incluindo a fabricação de sabão e a temática "água”, assim como outros aspectos.

Um dado intrigante na pesquisa realizada foi que pouco menos de $30 \%$ dos professores se sentiam aptos a trabalhar EA com os seus alunos, e quase dois terços se consideravam parcialmente aptos. Dois professores afirmaram que esta temática deveria ser trabalhada por uma pessoa capacitada a desenvolver este trabalho, indicando, provavelmente, uma concepção mais voltada aos aspectos técnicos específicos das ações relacionadas com a EA.

Tais alusões ao âmbito específico das questões técnicas corroboram as afirmações de Carvalho (2007) em relação às dificuldades que parte dos professores possui em relação ao conteúdo específico de ciências, revestindo-se de grande importância a inserção, nas pesquisas realizadas junto aos docentes, de questionamentos específicos que possibilitem verificar os conhecimentos prévios de química, física e biologia.

Quanto à metodologia a ser utilizada, os professores indicaram a preferência por oficinas, denotando uma vontade de participar mais ativamente do processo. As palestras e as saídas a campo foram indicadas como segunda e terceira possibilidades, sendo os temas preferidos os seguintes: os resíduos (lixo), a água e a relação do ser humano com o ambiente.

A consonância entre as estratégias utilizadas, os temas de eleição e as necessidades da comunidade proporciona o atendimento das principais demandas do contexto, indicando que o diagnóstico situacional aponta os caminhos a serem seguidos com base na articulação entre estes três elementos, unidos por práticas compartilhadas de construção. 
A escola representa um lócus privilegiado para a criação de processos colaborativos de resolução de problemas locais em sintonia com os grandes temas da contemporaneidade. Deste modo, a seleção de temáticas ambientais e as identidades dos sujeitos envolvidos no processo se constituem em componentes pedagógicos fundamentais para a construção de práticas educativas calcadas na experiência e na vivência da comunidade (Jacobi et al., 2009).

Por esta razão, a ação sistêmica no sistema educacional incluindo gestores, professores, alunos e a comunidade do entorno da escola é fundamental para a construção de práticas de formação continuada que resultem em melhorias efetivas no contexto educativo. Conforme Azevedo e Ramalho,

...entendemos que é relevante indagar sobre a ... [formação continuada] ... seus significados, limites e possibilidades na materialização de condições estruturais que resultem em lógicas, rotinas e planos mais democráticos dentro das ações cotidianas das escolas, transformando-as em locais de formação permanente, capazes de sustentar um projeto mais justo de educação e sociedade. (Azevedo e Ramalho, 2011, p. 43).

\section{Considerações finais}

As novas configurações da contemporaneidade no que tange ao processo educacional indicam que o papel do professor deve ser repensado constantemente, visando atender às necessidades cambiantes que caracterizam a sociedade contemporânea, na qual os saberes científicos são de relevância fundamental para o desenvolvimento social. A EA se inscreve na transversalidade de muitos domínios sociais, indicando o papel que ela desempenha - ou que deveria desempenhar - na escola, ou seja, construir a articulação entre as diferentes disciplinas, entre a escola e a comunidade e entre as demandas ambientais locais e as grandes questões globais.

Nessa perspectiva, os professores precisam estar habituados ao processo compartilhado, superando conflitos, compreendendo o contraditório e buscando uma ressonância maior com os bens coletivos. Da mesma forma, a construção de processos de formação continuada de professores não pode prescindir de um planejamento que possa coadunar os anseios, as necessidades e as peculiaridades da comunidade em questão.

A construção de um processo de formação docente compartilhada pressupõe "ouvir o outro", inclusive por meio da realização de uma pesquisa ampla com os professores, que realize um diagnóstico situacional da comunidade docente e indique, a partir de suas percepções e concepções, as lacunas existentes nas dimensões conceituais, atitudinais e procedimentais a serem enfatizadas na formação continuada. 
Reitera-se que a EA inclui a questão das atitudes e valores, mas também necessita, para as suas práticas, de um desenvolvimento conceitual que possa articular os domínios físicos, químicos, biológicos e sociais, proporcionando a inserção do processo nos amplos domínios do ensino de ciências e do contexto ambiental articulado com as peculiaridades educacionais dos anos iniciais do ensino fundamental.

Considerando que o desenvolvimento de saberes gera a construção de olhares diferenciados sobre fenômenos já conhecidos, a adoção de práticas de formação continuada que respeitem os saberes locais e que sejam calcadas em estudos detalhados dos fundamentos teóricos envolvidos proporciona a apropriação dos amplos domínios de saberes necessários para a realização de ações efetivas de EA.

Para realizar tais ações é imprescindível que formadores e docentes contribuam para o delineamento das atividades, respeitando suas diferenças e construindo a ampliação das ressonâncias que principiam com a vontade de produzir melhorias nas condições do ambiente e da educação. Assume-se, assim, o respeito ao "olhar do outro", não apenas como princípio abstrato, mas como norteador de práticas educativas que atendam às necessidades da escola, da região e do país.

\section{Referências}

AZEVEDO, Leny Cristina Soares Souza, RAMALHO, Maria Nailde Martins. Formação Continuada de professores: os desafios da construção de propostas político-pedagógicas. Linhas críticas, Brasília, UNB, v. 17, n. 32, p. 33-44, jan./abr. 2011.

BAUER, M. W. e GASKELL, G. Pesquisa qualitativa com texto, imagem e som. Petrópolis: Vozes, 2008.

BRASIL. Secretaria de Educação Fundamental. Parâmetros Curriculares Nacionais: Ciências Naturais primeira à quarta séries. Brasília: MEC/SEF, 1997.

BRASIL. Secretaria de Educação Fundamental. Parâmetros Curriculares Nacionais: Ciências Naturais - Temas transversais. MEC/SEF, 1998.

BRASIL. Lei no 9.795, de 27 de abril de 1999. Dispõe sobre a Educação Ambiental, institui a Política Nacional de EA e dá outras providências. Brasília, Presidência da República, 1999.

BRASIL. Ministério da Educação. Instituto Nacional de Estudos e Pesquisas Educacionais Anísio Teixeira. Sinopse do professor. 2009a. Disponível em: <http://portal.inep.gov.br/ basica-censo-escolar-sinopse-sinopse>. Acesso em: 5 ago. 2011.

BRASIL. Ministério da Educação. Instituto Nacional de Estudos e Pesquisas Educacionais Anísio Teixeira. Sinopse Estatística da Educação Básica. 2009b. Disponível em: <http:// portal.inep.gov.br/basica-censo-escolar-sinopse-sinopse>. Acesso em: 5 ago. 2011.

CARVALHO, Ana Maria Pessoa de. A pesquisa em sala de aula e a formação de professores. In: NARDI, Roberto (org.). A pesquisa em ensino de ciências no Brasil: alguns recortes. São Paulo: Escrituras, 2007. 
CARVALHO, Ana Maria Pessoa de, GIL-PÉREZ, Daniel. Formação de professores de ciências. São Paulo: Cortez, 2009.

CARVALHO, Isabel Cristina de Moura. A invenção ecológica: narrativas e trajetórias da Educação Ambiental no Brasil. Porto Alegre: UFRGS, 2004.

DIAS, Genebaldo Freire. Educação Ambiental: princípios e práticas. 9. ed. São Paulo: Gaia, 2004.

EINSFELD, Felipe, PROENÇA, Mariana de Souza, DAL-FARRA, Rossano André. Controle da dengue: reflexões sobre as contribuições da escola e da mídia. In: Encontro Nacional de Pesquisadores em Educação em Ciências, VII, 2009, Florianópolis, Anais do VII Encontro Nacional de Pesquisadores em Educação em Ciências, Florianópolis, 2009.

EL-HANI, Charbel, Niño, SEPÚLVEDA, Cláudia. Referenciais teóricos e subsídios metodológicos para a pesquisa sobre as relações entre educação científica e cultura. In: SANTOS, Flávia Maria Teixeira dos, GRECA, Ileana María (orgs.). A pesquisa em ensino de ciências no Brasil e suas metodologias. Ijuí: Unijuí, 2007, p. 161-212.

IMBERNÓN, Francisco. Formação continuada de professores. Porto Alegre: Artmed, 2010.

JACOBI, Pedro Roberto, TRISTÃO, Martha, GONÇALVES Maria Isabel Gonçalves Correa. A função social da Educação Ambiental nas práticas colaborativas: participação e engajamento. Caderno Cedes, Campinas, Unicamp, v. 29, n. 77, p. 63-79, jan./abr. 2009.

JíMENEZ ALEIXANDRE, Maria Pílar, FEDERICO AGRASO, Marta. A argumentação sobre questões sociocientíficas: processos de construção e justificação do conhecimento em sala de aula. Educação em Revista, Belo Horizonte, UFMG, v. 43, p. 13-33, jun., 2006.

KOLSTO, Stein Dankert. Science students' critical examination of scientific information related to socioscientific issues. 2005. Disponível em: <http://folk.uib.no/pprsk/Dankert/ Handouts/2005_Kolsto_et_al_Science_students'_critical_examination_ev.pdf $\rightarrow$. Acesso em: 7 dez. 2011.

KRASILCHIK, Myriam, MARANDINO, Martha. Ensino de ciências e cidadania. São Paulo: Moderna, 2004.

KRASILCHIK, Myriam. O professor e o currículo das ciências. São Paulo: EPU, 2006.

MALDANER, Otávio Aloísio, ZANON, Lenir Basso, AUTH, Milton Antonio. Pesquisa sobre Educação em Ciências e formação de professores. In: SANTOS, Flávia Maria Teixeira dos, GRECA, Ileana María (orgs.). A pesquisa em ensino de ciências no Brasil e suas metodologias. ljuí: Unijuí, 2007. p. 49-88.

MACEDO, Elizabeth, LOPES, Alice Casimiro. A estabilidade do conteúdo disciplinar: o caso das ciências. In: LOPES, Alice Casimiro, MACEDO, Elizabeth. Disciplinas e integração curricular: histórias e políticas. Rio de Janeiro: DP\&A, 2007. p. 73-94.

MONEREO, Carles, POZO, Juan. Ignacio. A prática de assessoramento educacional. Porto Alegre: Artmed, 2007.

MOREIRA, Marcos. Antônio. A área de ensino de ciências e matemática na CAPES: panorama 2001/2002 e critérios de qualidade. Revista Brasileira de Pesquisa em Educação em Ciências, v. 2, n. 1, p. 36-59, 2002. 
PENTEADO, Heloísa. Dupas. Meio ambiente e a formação de professores. 5. ed. São Paulo: Cortez, 2003.

POZO, Juan Ignácio, CRESPO, Miguel Angel Gomes. Aprender y enseñar ciencia. Madrid: Morata, 2000.

SANTOS, Wildson Luis Pereira dos, MORTIMER, Eduardo Fleury. Abordagem de aspectos sociocientíficos em aulas de ciências: possibilidade e limitações. Investigações em Ensino de Ciências, Porto Alegre, UFRGS, v. 14, n. 2, p. 191-218, ago, 2009.

UNESCO. Relatório de monitoramento de educação para todos. Brasil 2008: educação para todos em 2015; alcançaremos a meta? Brasília: UNESC0, 2008. Disponível em: <http:// unesdoc.unesco.org/images/0015/001592/159294por.pdf>. Acesso em: 7 ago. 2011.

VALDUGA, Mariela. Percepções e concepções dos professores da Educação Infantil e do ensino fundamental sobre Formação Docente Continuada em Educação ambiental. Canoas: ULBRA, 2011. Monografia (Especialização em Novas Tecnologias e Metodologias no Ensino de Ciências da Natureza), Programa de Pós-Graduação em Ensino de Ciências e Matemática da Universidade Luterana do Brasil, 2011.

VALDUGA, Mariela, DAL-FARRA, Rossano André. Formação Docente Continuada e Educação Ambiental: construindo práticas compartilhadas. In: Encontro Nacional de Pesquisadores em Educação em Ciências, VIII, 2011, Campinas, Anais do VIII Encontro Nacional de Pesquisadores em Educação em Ciências, Campinas, 2011.

ZAKZEVSKI Sônia Balvedi, SATO, Michéle. Historiando a dimensão ambiental nos programas escolares gaúchos. Pesquisa em Educação Ambiental, São Carlos, UFSCAR, v. 2, n. 2, p. 109-132, jul-dez, 2007.

Recebida 1a versão em outubro de 2011

Aprovada 2a versão em maio de 2012

Rossano André Dal-Farra, licenciado em Ciências/Biologia e Medicina Veterinária. Mestre em Zootecnia-Melhoramento Genético Animal. Doutor em Educação. Professor e pesquisador da Universidade Luterana do Brasil (ULBRA), atuando também no Programa de Pós-Graduação em Ensino de Ciências e Matemática da Instituição. Tem experiência em pesquisa na Área de Ensino de Ciências e em Genética, atuando principalmente nos seguintes temas: Educação, Ensino de Ciências, Educação Científica e História da Ciência. E-mail: rossanodfauol.com.br

Mariela Valduga, Licenciada em Ciências Biológicas. Especialista em Novas Tecnologias e Metodologias em Ensino de Ciências. Professora da Rede Pública de Ensino de Encantado/ RS. E-mail: marielavaldugađayahoo.com.br 